\title{
Effect Analysis of Service Supply Chain with Dynamic Game under the Condition of Sensitive Demand
}

\author{
Guanglan $\mathrm{Zhou}^{1,2}$ and Chunhua $\mathrm{Ju}^{2,3}$ \\ ${ }^{1}$ School of Business Administration, Zhejiang Gongshang University, Hangzhou 310018, China \\ ${ }^{2}$ Center for Studies of Modern Business, Zhejiang Gongshang University, Hangzhou 310018, China \\ ${ }^{3}$ School of Computer Science \& Information Engineering, Zhejiang Gongshang University, Hangzhou 310018, China \\ Correspondence should be addressed to Guanglan Zhou; guanglanzhou@zjgsu.edu.cn
}

Received 8 December 2014; Revised 10 April 2015; Accepted 12 April 2015

Academic Editor: Chaudry Masood Khalique

Copyright (C) 2015 G. Zhou and C. Ju. This is an open access article distributed under the Creative Commons Attribution License, which permits unrestricted use, distribution, and reproduction in any medium, provided the original work is properly cited.

Under the real circumstances of service supply chain, there is one demand appearing as the sensitive feature, to face the increasing uncertainty. It could be elaborated upon the decision variables such as price, quantity, and efforts. The member behaviors are operated and coordinated in the process of multiperiod dynamic game. Based on the multiperiod dynamic game theory, the service demand and price, quantity of goods, and efforts of members in the secondary service supply chain are considered. The paper discusses the reputation effect and ratchet effect in the multiperiod dynamic game service supply chain. Additionally, the paper describes this problem, builds a programming model based on the multiperiod dynamic game, and deduces the optimal solution. Furthermore, the paper analyzes the impact of reputation effect and ratchet effect on the agent's revenue. Through the simulation, it is found that the agency efforts are a combination result of reputation effect and ratchet effect in the process of multiperiod dynamic game. Through the long-term dynamic game, the short-term moral risk in service supply chain can be restrained so that the result under the asymmetric information is the same as that under the complete information.

\section{Introduction}

Service supply chain with dynamic game in academia is a topic of growing importance. In the field of international logistics, these significant characteristics of member behaviors are often mentioned and further elaborated on, such as long-term and dynamic game. The current service level affects the decision of that in next period, while the effort level of the logistics service provider and agent affects the market demand. Therefore, this paper will discuss the multiperiod problem in sensitive (such as demand and prices, quantity, and efforts) service supply chain management from the time perspective of service supply chain. The original contribution is that the agency efforts are a combination result of reputation effect and ratchet effect. Simply put, the short-term moral risk in service supply chain can be restrained through the long-term dynamic game.

\section{Literature Review}

First of all, the multiperiod problem can be known through the development of dynamic principal-agent theory. The earliest principal-agent dynamic model was proposed by Radner [1] and Rubinstein [2]. Through repeated game model, they proved if the principal and agent had long-term relationships and enough confidence, the one-period Paretooptimal risk sharing and incentive was achievable. When the agent's behavior is difficult, even unable to confirm, and the explicit incentive mechanism is hard to implement, the longterm principal-agent relationship has a lot of advantages, which can make use of the reputation effect. The model built by Radner [1] and Rubinstein [2] explained this process exhaustively. But the reputation effect issue was clearly identified and put forward by Fama [3]. He attempted to explain how the segmentation of security ownership and control can be an efficient form of economic organization. What he thought was that incentive problem had been exaggerated 
in the principal-agent literature review. However, "time" can actually solve this problem because of the agent market restraining on the agent. And he stressed this point, which was different from Radner [1] and Rubinstein [2]. Holmstrom and Costa [4] studied that the principal regarded the past performance of the same agent as a standard, which contained much useful information. That is to say, the past performance was related to the managers' subjective efforts. The harder the agent worked, the greater chance of good performance would be. In other words, the standard was higher and higher set by the managers themselves. When they realized that the efforts resulted in the standard levelling up, their enthusiasm towards work would be depressed. The effort aversion could induce a natural discrepancy in uncertainty preferences. Such standard performance rising tendency was called the ratchet effect. Furthermore, there were also many scholars who studied the dynamic principal-agent theory. Their researches were closer to reality. In the multiperiod multistage supply chain, there existed complex interaction between and among members, especially in the networking supply chain system. The interaction between the bounded rationality of decisionmaker and feedback information and time delay could both lead to the complex dynamic behavior. Thus, the behavior and decision-making coordination among complex supply chain members became a new research interest [5]. The cascaded structure of a production-distribution chain can produce a wide variety of dynamic behaviors. Additionally, Agrell et al. [6] studied the revenue sharing contract coordination strategy of three kind decision models of ordering problem in supply chain on the basis of the telecom supply chain. They were centralized decision model, supplier's dominant decentralized decision model, and manufacturer's dominant decentralized decision model, respectively. A minimal agency model was used to contrast known optimal mechanisms with the actual practice in the telecommunications industry. Monahan et al. [7] studied the agent's dynamic pricing problem under the symmetric information. They presented the optimal solution of the demand function in the form of multiplication and analyzed its attribution and solution algorithm.

What is more, there were many Chinese scholars who studied this issue. Wang [8] studied the phenomenon under the asymmetry information in supply chain and the principle of realizing supply chain coordination by using the contract mechanism. Shaohua [9] studied the behavior coordination in multiechelon multistage supply chain. After summarizing studies on supply chain coordination, a feedback model of multistage multiechelon supply chain system was set up. Ma and Zhou [10] analyzed the performances of the supply and demand, probability of the model being put into practice, and designed a dynamic quantity flexibility contract on the assumption that forecast-precision and transfer-price were linearly changing with time. Zhongkai et al. [11] studied the coordination problem in a supply chain of the dynamic pricing set from the manufacture and also found that the combination of revenue sharing contract and rebate contract could coordinate the supply chain. This research was based on the study of Monahan et al. [7], which also belonged to the area of dynamic coordination problem under the symmetry information. Based on the signaling model of information economics, Jin et al. [12] discussed that venture capitalist avoided and controlled the entrepreneur adverse selection risk by using signaling model during successive period of multiperiod venture capital. Ming and Ningjie [13] studied the dynamic game model between supplier and retailer under the asymmetry information and analyzed the effect of explicit and implicit incentive mechanisms. Although Weng's paper was not perfect, the analysis of dynamic principal-agent under the asymmetric information in his paper was of great value. Based on the research of Agrell et al. [6], whose research took telecommunications industry as example, Nie and Xiong [14] studied the investment decision and ordering strategies in two-period telecom supply chain with demand uncertainty. The optimal ordering quantities and revenue sharing rates were given and the ordering quantities in three ordering strategies were compared. In addition, Shaochun et al. [15] constructed a game model of opinion dynamics evaluation and analyzed the formation and dynamic development of herd behavior in the opinion evolutionary process. Rufei and Jia [16] considered the duopolistic differential game model on how technology spillover and technology update affect firm's R\&D strategy. And K. Wang and S. Wang [17] had an insight into the asymmetry information factors such as different price interval and various psychological pressures in the typical tristages bargaining game analysis. All of them investigated the multiperiod game problem.

To sum up, this paper will build a multiperiod dynamic game model under the condition of sensitive demand such as price, quantity, and members' efforts in the secondary service supply chain and consequently analyze its reputation effect and ratchet effect.

\section{The Description of Service Supply Chain with Dynamic Game Model}

3.1. The Definition of the Variables in the Model. Before describing the model, there are some definitions below denoted by characters.

$a$ : the market capacity. Assume that the market capacity of each period is the same.

$\gamma$ : the ability of the agent. The ability in the paper only refers to the ability to affect the market and it does not change over time.

$t$ : the trade period of the service provider and the agent.

$e_{t}$ : the agency efforts of the agent in $t$ period.

$\varepsilon_{t}$ : an exogenous random variable. It represents the uncertainty of technology or market in $t$ period. And its probability density is $f\left(\varepsilon_{t}\right)$.

$\pi_{t}$ : the profit of the whole supply chain in $t$ period.

$\delta$ : the discount factor.

$\pi_{r}$ : the profit that was assigned to the agent in $t$ period.

$c\left(e_{t}\right)$ : the negative effects of efforts brought to the agent, that is, the agency cost. 
$U$ : the utility of the agent.

$V:$ the utility of the service provider.

$W$ : the revenue of the whole supply chain.

$E\left(\gamma \mid \pi_{t-1}\right)$ : the reputation of the agent in $t$ period. It means the expectations about $\gamma$ of the service provider.

$b$ : the agent's bargaining power, that is, the share of the profits it gains from its reputation $E\left(\gamma \mid \pi_{t-1}\right)$.

$\phi_{t}$ : the share of the profits the agent obtained from the excess part in performance.

3.2. Model Description. There are two participants in the secondary service supply chain of international logistics business, international logistics service provider, referred to as service provider, and international logistics agent, referred to as agent. The service provider manages the service products, which can determine the service level $\left(\theta_{t}\right)$ and cause certain service cost $c\left(\theta_{t}\right)$. The service products are sold to the agent with wholesale price $\left(w_{t}\right)$ by the service provider. The agent can order from the service provider according to the market demand $\left(D_{t}\right)$ and the quantity is described as $Q_{t}$. The agent can also implement agency activities on the service products of service provider. And the agency efforts $\left(e_{t}\right)$ of the agent will bring the agency cost $c\left(e_{t}\right)$ accordingly. Since then, the agent sells the service products to the consumer with the retail price $\left(p_{t}\right)$ and gets profit. And the service provider and agent make decisions based on the principle of expected profit maximization. The service provider is the leader and the agent is the follower in the game. With the revenue-sharing contract, the service provider sells the products to the agent on a wholesale price $\left(w_{t}\right)$, which is equal to the cost of the service provider $c\left(w_{t}=c\right)$ in general. Throughout the game, the service provider, as a leader, guides the agent to make efforts they expected by providing appropriate incentive contracts. When the agent observes the decisions, that is, to say, the contract, made by service provider, it sees the contract as a constraint condition and makes the efforts which can maximize its own utility. Then, the service provider comes up with a new contract according to the performance update beliefs of the agent. And under the constraint of the new contract, the agent makes the efforts which can maximize its own utility again. And so forth, a multiperiod dynamic game problem of a service supply chain is produced. The model could be illustrated in Figure 1.

3.3. Model Assumptions. (1) There exists unilateral asymmetric information in the supply chain. That is, the service provider cannot see the ability $(\gamma)$ of the agent. It only knows its distribution: $Y \sim N\left(\bar{\gamma}, \sigma_{\gamma}^{2}\right)$. And the ability of both sides, $\lambda$ and $\gamma$, does not change with time.

(2) The service cost is constant and the lead time of order is zero. That is, the order requirements of the agent can be met immediately.

(3) The stock-out rate is 0 . That is, there is no out of stock.

(4) The decisions are decentralized in the supply chain. The service provider and agent are independent economic entity and they both are risk neutral.
(5) $\varepsilon_{t} \sim\left(0, \sigma_{\varepsilon}^{2}\right), \lambda, \varepsilon_{1}$, and $\varepsilon_{2}$ are independent of each other.

(6) The agency cost is $c\left(e_{t}\right)=\eta e_{t}^{2} / 2$. And when $c\left(e_{t}\right)>0$, $c^{\prime}\left(e_{t}\right)>0$, and $c^{\prime \prime}\left(e_{t}\right)>0, \eta(\eta>0)$ is the coefficient of agency cost. The bigger the coefficient is, the greater of the cost will be with the same agency efforts $e_{t}$. This assumption is the same as the agency cost assumption of single-period. The service cost of the service provider in each period is $c\left(\theta_{t}\right)=\zeta \theta_{t}^{2} / 2$. When $c\left(\theta_{t}\right)>0, c^{\prime}\left(\theta_{t}\right)>0$, and $c^{\prime \prime}\left(\theta_{t}\right)>0, \zeta(\zeta>0)$ is the coefficient of service cost. The bigger the coefficient is, the greater of the cost will be with the same service efforts $\theta_{t}$.

(7) The market demand $\left(D_{t}\right)$ shows the linear correlation on the quantity with variables such as price, quantity, and efforts. The selling price of the agent $\left(p_{t}\right)$, agency efforts $\left(e_{t}\right)$, service efforts $\left(\theta_{t}\right)$, wholesale price $\left(w_{t}\right)$, and the market random variable $\varepsilon_{t}$ all affect the demand. Therefore, the dynamic market demand $D_{t}$ can be described as follows:

$$
D_{t}=a-p_{t}+\gamma e_{t}+\lambda \theta_{t}+\varepsilon_{t} .
$$

Assume that the order is made according to the market demand; that is, $D_{t}=Q_{t}$. Thus, the revenue of the whole supply chain is

$$
\begin{aligned}
& \pi_{t}=p_{t} \cdot Q_{t}-\frac{\eta e_{t}^{2}}{2}-\frac{\zeta \theta_{t}^{2}}{2} \\
& \pi_{t}=p_{t} \cdot\left(a-p_{t}+\gamma e_{t}+\lambda \theta_{t}+\varepsilon_{t}\right)-\frac{\eta e_{t}^{2}}{2}-\frac{\zeta \theta_{t}^{2}}{2} .
\end{aligned}
$$

(8) In the initial state, the agent has not yet established the reputation of its own capabilities. So it needs trade to convey the information about its own capabilities. When the incentive contracts provided by the service provider meet to the agent participation constraint, the agent will accept the incentive contracts. Thus, the adverse selection problem cannot be considered. This assumption is reasonable. Just as college students who have just graduated from school, they often have to accept a lower salary job temporarily even if they are very outstanding [13].

(9) In every period, the service provider can provide the agent with explicit incentive contracts which meet their participation constraint. That is, $E\left(U_{t}\right) \geq \bar{U}, \bar{U}$ is reservation utility of the agent. But the service provider cannot promise long-term contract because it will make the second-period contract according to the performance in the first period.

\section{Programming Equation}

4.1. Incentive Contracts. In multiperiod dynamic principalagent, the incentive contracts that the service provider provided to the agent include not only the explicit incentive such as revenue sharing, but also the implicit incentive due to the good reputation. The explicit incentive refers to the fact that the principal can reward or punish the agent according to the observed action results. So the service provider can induce the agent to choose the action it expects. In the revenue sharing contract model, $\pi_{t}$ is the common knowledge of the service provider and the agent. Thus, $\pi_{t}-E\left(\pi_{t} \mid \pi_{t-1}\right)$ (the extra amount that the actual performance excessing the 


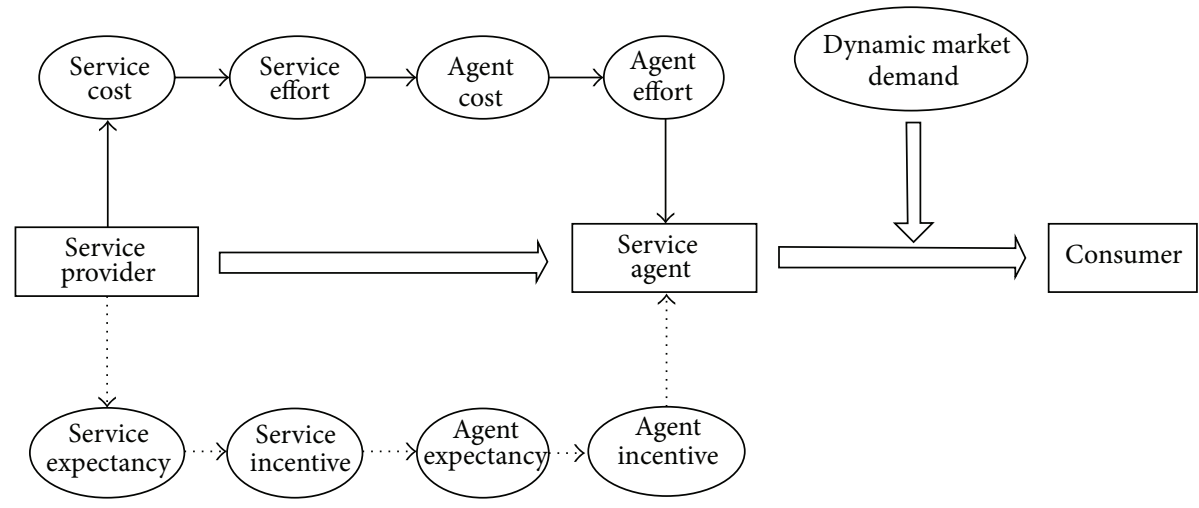

FIGURE 1: The service supply chain with dynamic game model.

expected performance) is an observable result. Then $\phi_{t}\left[\pi_{t}-\right.$ $\left.E\left(\pi_{t} \mid \pi_{t-1}\right)\right]$ is the explicit incentive that the service provider provided to the agent in $t$ period. In addition, according to Fama's study, the market value of the agent (even its income) depends on its past performance. If the principalagent relationship can last many times, even in the absence of explicit incentive, the agent also has the enthusiasm to work hard because it helps to improve their reputation and increase the income in the future. Therefore, $b E\left(\gamma \mid \pi_{t-1}\right)$ is the implicit incentive that the service provider provided to the agent in $t$ period.

To sum up, the pay $T$ that the service provider provided to the agent in $t$ period is

$$
T=\phi_{t}\left[\pi_{t}-E\left(\pi_{t} \mid \pi_{t-1}\right)\right]+b E\left(\gamma \mid \pi_{t-1}\right) .
$$

Equation (3) is the incentive contract that the service provider provided in $t$ period. The first part is the explicit incentive and the second part is the implicit incentive.

4.2. The Expected Utility of the Agent. According to the assumptions above, the two-stage expected utility function of the agent is

$$
\begin{aligned}
E(U) & =\sum_{t=1}^{2} \delta^{(t-1)} E\left(U_{t}\right) \\
& =\sum_{t=1}^{2} \delta^{(t-1)} \int\left[T-c\left(e_{t}\right)\right] f\left(\varepsilon_{t}\right) d \varepsilon_{t} .
\end{aligned}
$$

What the agent needs to do is that to select the appropriate quality inspection effort $e_{t}$ in $t$ period to make its own expected utility maximization in the whole period with the incentive contracts provided by the service provider; that is

$$
\begin{aligned}
& \max E(U)=\sum_{t=1}^{2} \delta^{(t-1)} \\
& \quad \cdot \int\left\{\phi_{t}\left[\pi_{t}-E\left(\pi_{t} \mid \pi_{t-1}\right)\right]+b E\left(\gamma \mid \pi_{t-1}\right)-c\left(e_{t}\right)\right\} \\
& \quad \cdot f\left(\varepsilon_{t}\right) d \varepsilon_{t} .
\end{aligned}
$$

To integrate (5), we can get (6) as follows:

$$
\begin{aligned}
\max & E(U)=\sum_{t=1}^{2} \delta^{(t-1)}\left\{\phi _ { t } \left[p_{t} \cdot\left(a-p_{t}+\gamma e_{t}+\lambda \theta_{t}+\varepsilon_{t}\right)\right.\right. \\
- & \left.\frac{\eta e_{t}^{2}}{2}-\frac{\zeta \theta_{t}^{2}}{2}-E\left(\pi_{t} \mid \pi_{t-1}\right)\right]+b E\left(\gamma \mid \pi_{t-1}\right) \\
- & \left.\frac{\eta e_{t}^{2}}{2}\right\}
\end{aligned}
$$

This is a multistage decision problem. When the agent makes decisions in every stage, he must consider the effect of current decisions on the utility of subsequent stage.

The agency efforts that were selected by the agent in every stage affect the utility of next stage by influencing the belief of the service provider. And take the two state parameters of the agent in $t$ period, $\phi_{t}\left[\pi_{t}-E\left(\pi_{t} \mid \pi_{t-1}\right)\right]$ and $b E\left(\gamma \mid \pi_{t-1}\right)$, as vector which is in accordance with Markov property.

4.3. The Expected Utility of the Service Provider. The service provider maximizes its own expected utility by providing incentives to the agent. And the expected utility of the service provider is

$$
\begin{aligned}
& E(V)=\sum_{t=1}^{2} \delta^{(t-1)} E\left(V_{t}\right)=\sum_{t=1}^{2} \delta^{(t-1)} \\
& \quad \cdot \int\left\{\left(1-\phi_{t}\right)\left[\pi_{t}-E\left(\pi_{t} \mid \pi_{t-1}\right)\right]-b E\left(\gamma \mid \pi_{t-1}\right)\right. \\
& \left.\quad-c\left(\theta_{t}\right)\right\} f\left(\varepsilon_{t}\right) d \varepsilon_{t} .
\end{aligned}
$$

The goal of the service provider is to maximize the expected utility; that is

$$
\begin{aligned}
& \max E(V)=\sum_{t=1}^{2} \delta^{(t-1)} \int\left\{\left(1-\phi_{t}\right)\left[\pi_{t}-E\left(\pi_{t} \mid \pi_{t-1}\right)\right]\right. \\
& \left.-b E\left(\gamma \mid \pi_{t-1}\right)-c\left(\theta_{t}\right)\right\} f\left(\varepsilon_{t}\right) d \varepsilon_{t} .
\end{aligned}
$$


To integrate (8), we can get (9) as follows:

$$
\begin{aligned}
& \max E(V)=\sum_{t=1}^{2} \delta^{(t-1)}\left\{( 1 - \phi _ { t } ) \left[p_{t}\right.\right. \\
& \cdot\left(a-p_{t}+\gamma e_{t}+\lambda \theta_{t}+\varepsilon_{t}\right)-\frac{\eta e_{t}^{2}}{2}-\frac{\zeta \theta_{t}^{2}}{2} \\
& \left.\left.-E\left(\pi_{t} \mid \pi_{t-1}\right)\right]-b E\left(\gamma \mid \pi_{t-1}\right)-\frac{\eta \theta_{t}^{2}}{2}\right\} .
\end{aligned}
$$

Assume that the service provider has rational expectations, and the agency efforts of the agent are $\bar{e}_{t}=E\left(e_{t} \mid \pi_{t-1}\right)$. Then $\tau$ can be described as $\tau=\sigma_{\gamma}^{2} /\left(\sigma_{\gamma}^{2}+\sigma_{\varepsilon}^{2}\right)$. The bigger the value of $\tau$ is, the greater proportion of $\gamma$ in $\pi_{1}$ observed [3]. The following state transition equations can be gained according to the rational expectation formula:

$$
\begin{aligned}
E\left(\gamma \mid \pi_{t-1}\right)= & (1-\tau) E\left(\gamma \mid \pi_{t-2}\right)+\tau\left(\pi_{t-1}-\bar{e}_{t-1}\right) \\
E\left(\pi_{t} \mid \pi_{t-1}\right)= & (1-\tau) E\left(\gamma \mid \pi_{t-2}\right)+\tau\left(\pi_{t-1}-\bar{e}_{t-1}\right) \\
& +\bar{e}_{t} .
\end{aligned}
$$

Assume that $\pi_{0}$ represents the initial state; then

$$
\begin{aligned}
E\left(\gamma \mid \pi_{0}\right)= & E(\gamma)=\bar{\gamma} \\
E\left(\pi_{1} \mid \pi_{0}\right)= & E\left(\pi_{1}\right) \\
= & p_{1} \cdot\left(a-p_{1}+\gamma e_{1}+\lambda \theta_{1}+\varepsilon_{1}\right)-\frac{\eta e_{1}^{2}}{2} \\
& -\frac{\zeta \theta_{1}^{2}}{2} .
\end{aligned}
$$

4.4. Programming Equation. According to the expected utility of the service provider, the expected utility of the agent, and the initial state, the dynamic multi-period planning equation of which the service provider provided explicit and implicit incentives to the agent when the ability of the agent is unknown is as follows:

$$
\max _{\theta_{t}, \phi_{t}} E(V)
$$

S.t:

$$
\begin{aligned}
\left(p_{t}, e_{t}\right) & \in \max E(U) \\
E\left(U_{t}\right) & \geq \bar{U} \\
E\left(\gamma \mid \pi_{0}\right) & =\bar{\gamma} \\
E\left(\pi_{1} \mid \pi_{0}\right) & =p_{1} \cdot\left(a-p_{1}+\gamma e_{1}+\lambda \theta_{1}+\varepsilon_{1}\right)-\frac{\eta e_{1}^{2}}{2} \\
& -\frac{\zeta \theta_{1}^{2}}{2} .
\end{aligned}
$$

Combined with (7) and (8), the result is

$$
\begin{gathered}
\max _{\theta_{t}, \phi_{t}} E(V)=\sum_{t=1}^{2} \delta^{(t-1)}\left\{( 1 - \phi _ { t } ) \left[p_{t}\right.\right. \\
\cdot\left(a-p_{t}+\gamma e_{t}+\lambda \theta_{t}+\varepsilon_{t}\right)-\frac{\eta e_{t}^{2}}{2}-\frac{\zeta \theta_{t}^{2}}{2} \\
\left.\left.-E\left(\pi_{t} \mid \pi_{t-1}\right)\right]-b E\left(\gamma \mid \pi_{t-1}\right)-\frac{\eta \theta_{t}^{2}}{2}\right\} .
\end{gathered}
$$

S.t:

$$
\begin{aligned}
& \left(p_{t}, e_{t}\right) \in \sum_{t=1}^{2} \delta^{(t-1)}\left\{\phi _ { t } \left[p_{t} \cdot\left(a-p_{t}+\gamma e_{t}+\lambda \theta_{t}+\varepsilon_{t}\right)\right.\right. \\
& \left.-\frac{\eta e_{t}^{2}}{2}-\frac{\zeta \theta_{t}^{2}}{2}-E\left(\pi_{t} \mid \pi_{t-1}\right)\right]+b E\left(\gamma \mid \pi_{t-1}\right) \\
& \left.\quad-\frac{\eta e_{t}^{2}}{2}\right\} \\
& E\left(U_{t}\right) \geq \bar{U} \\
& E\left(\gamma \mid \pi_{0}\right)=\bar{\gamma} \\
& E\left(\pi_{1} \mid \pi_{0}\right)=p_{1} \cdot\left(a-\bar{p}_{1}+\bar{\gamma} \bar{e}_{1}+\lambda \bar{\theta}_{1}\right)-\frac{\eta \bar{e}_{1}^{2}}{2}-\frac{\zeta \bar{\theta}_{1}^{2}}{2} .
\end{aligned}
$$

4.5. Computation and Analysis of Equation. Establish the objective function and solve its Bellman equation; the service efforts and revenue sharing coefficient of the service provider in $t$ period are as follows:

$$
\begin{aligned}
& \Phi_{t} \\
& =\frac{\underline{U}_{R}}{\left(\zeta K_{t}(a-c)\right) /\left(\zeta-K_{t} \lambda^{2}\right)+\delta \tau \cdot \Phi_{t-1} \cdot\left[b-\left(\zeta\left(\theta_{t}\right)^{2} / 2 \eta\right)\right]} \\
& \theta_{t}=\frac{\lambda K_{t}(a-c)}{\left(\zeta-K_{t} \lambda^{2}\right)}+\frac{\delta \tau}{\eta}\left[b-\theta_{t-1} \cdot \frac{\lambda\left(K_{t}-K_{t-1}\right)(a-c)}{\left(\zeta-K_{t} \lambda^{2}\right)}\right] .
\end{aligned}
$$

Assume that the variables $\Phi_{0}$ and $\theta_{0}$ are known, so the service efforts and revenue sharing coefficient of the service provider in $t$ period can be solved.

Getting the partial derivative of $E(V)$ for $p$ and $e$, the results are

$$
\begin{aligned}
& p_{t}^{*}=p\left(\Phi_{t}^{*}, \theta_{t}^{*}\right) \\
& e_{t}^{*}=e\left(\Phi_{t}^{*}, \theta_{t}^{*}\right) .
\end{aligned}
$$

Combined (17) with the objective function, the result is

$$
e_{t}^{*}=\frac{\gamma}{a \eta}\left\{\Phi_{t}^{*} \cdot \theta_{t}{ }^{*}+\delta \tau\left[b-\Phi_{t+1}^{*} \cdot\left(1+\frac{\Phi_{t+1}^{*}}{a \eta}\right)\right]\right\} .
$$

The agency efforts $e_{t}^{*}$ consist of two parts. One is $(\gamma / a \eta)$. $\Phi_{t}{ }^{*} \cdot \theta_{t}{ }^{*}$. It is related to the decision of this stage and belongs to the explicit incentive of the agent. The other one is $(\gamma / a \eta)$. $\delta \tau\left[b-\Phi_{t+1}^{*} \cdot\left(1+\Phi_{t+1}^{*} / a \eta\right)\right]$. It is not related to the decision of this stage and belongs to the implicit incentive of the agent. 


\section{Effect Analysis of Reputation Effect and Ratchet Effect}

The agent revenue includes not only the explicit incentive but also the implicit incentive. And the implicit incentive is the result of the interaction of two effects: reputation effect and ratchet effect. In the agency efforts, the reputation effect and ratchet effect, respectively, are $\gamma \delta \tau b / a \eta,-\left[(\gamma \delta \tau / a \eta) \cdot \Phi_{t+1}^{*} \cdot(1+\right.$ $\left.\left.\Phi_{t+1}^{*} / a \eta\right)\right]$.

5.1. The Reputation Effect. The reputation effect refers to the fact that the agency efforts in some stage will bring more revenue to the next stage. Hence, it can motivate the agent to strengthen the agency efforts continuously so as to obtain a better reputation and generate more revenue in the next stage.

According to the reputation effect $\gamma \delta \tau b / a \eta$, we can find that when the agent's bargaining power is stronger, and the values of management ability $(\gamma)$, discount factor $(\delta)$, and $\tau$ are larger, the agent is more motivated to improve agency efforts because it will lead to a better reputation and benefits.

When the values of market capacity $a$ and cost coefficient $\eta$ are smaller, the agent will have more agency efforts to bring a better reputation and benefits. The smaller the market capacity $a$ is, the greater influence the agent will have in the market. While the smaller the cost coefficient $\eta$ is, the lower cost the agent will pay with the same efforts.

5.2. The Ratchet Effect. The ratchet effect refers to the fact that the performance evaluation of principal on the agent in a certain stage is based on its performance in the last stage. Thus, in order to avoid taking on too much performance task in this stage, the agent will reduce the efforts in the previous stage. The ratchet effect belongs to the implicit incentive. It has nothing to do with the decisions of this stage but related to the decisions of next stage.

The ratchet effect is $-\left[(\gamma \delta \tau / a \eta) \cdot \Phi_{t+1}^{*} \cdot\left(1+\Phi_{t+1}^{*} / a \eta\right)\right]$ in the agency efforts. And we can find that the bigger the revenue sharing coefficient $\Phi_{t+1}^{*}$ is in the next stage, the lower the agency efforts will be in this stage. This is because the agent is enhancing the reserved space for its future performance. When the $\Phi_{t+1}^{*}$ is larger, it means that the distribution of income is higher in the next stage.

At the same time, when the agent's bargaining power is stronger, and the values of management ability $(\gamma)$, discount factor $(\delta)$, and $\tau$ are larger, the agent will reduce agency efforts because its result is that the ratchet effect is obvious, which can achieve the goal of concealing its ability. When the performance is not outstanding in this stage, the expectation of the service provider will reduce accordingly, and this leaves room for the performance enhancements in the next stage. While the values of market capacity $a$ and cost coefficient $\eta$ are smaller, the agent will reduce its agency efforts. Its starting point is to reduce the performance of this stage and leave room for performance enhancements in the next stage.

\section{Conclusion}

Under the real circumstances of the service supply chain, the member behaviors are operated and coordinated in the process of multiperiod dynamic game. The paper considers some variables, such as price, quantity, efforts, and market demand, the characteristics of which could be regarded as sensitive ones. Based on the dynamic game theory and the revenue sharing model, the paper builds a service supply chain model with multiperiod dynamic game. In addition, the paper elaborates the reputation effect and ratchet effect and also illustrates both explanations.

Though the simulation, it is found that the agency efforts are a combination result of reputation effect and ratchet effect in the process of multiperiod dynamic game. It also indicates the importance of reputation in the multiperiod supply chain. Through the long-term dynamic game, the short-term moral risk in service supply chain can be restrained so that the result under the asymmetric information is the same as that under the complete information.

\section{Conflict of Interests}

The authors declare that there is no conflict of interests regarding the publication of this paper.

\section{Acknowledgments}

This research is supported by Humanity and Sociology Foundation of Ministry of Education of China (nos. 14YJCZH226, 14JJD630011, and 11YJC630019), Foundation of Department of Education of Zhejiang Province (Y201329545), Zhejiang Science and Technology Plan Project (no. 2010C33016, 2012R10041-09), Key Laboratory of Electronic Business and Logistics Information Technology of Zhejiang Province (2011E10005), Innovative Group of e-Business Technology of Zhejiang Province (2010R50041), Natural Science Foundation of China (no. 71203196), and Zhejiang Provincial Natural Science Foundation of China (nos. LY14F020002, Y7100673, LY12G03015, and LQ12G01007).

\section{References}

[1] R. Radner, "Monitoring cooperative agreements in a repeated principal-agent relationship," Econometrica, vol. 49, no. 5, pp. $1127-1148,1981$.

[2] A. Rubinstein, "Equilibrium in supergames with the overtaking criterion," Journal of Economic Theory, vol. 21, no. 2, pp. 16-29, 1979.

[3] E. F. Fama, "Agency problems and the theory of the firm," Journal of Political Economy, vol. 88, no. 2, pp. 288-307, 1980.

[4] B. Holmstrom and J. R. I. Costa, "Managerial incentives and capital management," The Quarterly Journal of Economics, vol. 101, no. 4, pp. 835-860, 1986.

[5] E. R. Larsen, J. D. W. Morecroft, and J. S. Thomsen, "Complex behaviour in a production-distribution model," European Journal of Operational Research, vol. 119, no. 1, pp. 61-74, 1999.

[6] P. J. Agrell, R. Lindroth, and A. Norrman, "Risk, information and incentives in telecom supply chains," International Journal of Production Economics, vol. 90, no. 1, pp. 1-16, 2004.

[7] G. E. Monahan, N. C. Petruzzi, and W. Zhao, "The dynamic pricing problem from a newsvendor's perspective," Manufacturing and Service Operations Management, vol. 6, no. 1, pp. 73-91, 2004 . 
[8] X. Wang, "Contract incentives, information sharing and the dynamic coordination of supply chain," Management World, no. 4, pp. 106-115, 2005.

[9] L. Shaohua, "Behavior coordination in Multi-Echlon-MultiStage supply chain,” Logistics Sci-Tech, no. 29, pp. 127-129, 2006.

[10] S. Ma and J. Zhou, "A quantity flexibility supply contract with time flexibility," Storage,Transportation \& Preservation of Commodities, no. 2, pp. 1-4, 2007.

[11] X. Zhongkai, L. Gendao, T. Yanchang, and L. Wei, "Research on channel coordination problem on the internet with dynamic pricing," Journal of Industrial Engineering and Engineering Management, vol. 21, no. 3, pp. 49-55, 2007.

[12] Y. Jin, X. Ci, Z. Ye, and Y. Xi, "Design of multi-period dynamic signaling contract in venture capital," Journal of Shanghai Jiaotong University, vol. 38, no. 3, pp. 434-437, 2004.

[13] W. Ming and L. Ningjie, "Dynamic incentive contracts in the supply chain under information asymmetry," Journal of Guangxi University of Finance and Economics, vol. 21, no. 2, pp. 25-29, 2008.

[14] J. Nie and Z. Xiong, "Ordering strategies in two-period telecom supply chain with demand uncertainty," Industrial Engineering Journal, vol. 12, no. 1, pp. 17-23, 2009.

[15] H. Shaochun, L. Yun, Z. Yanchao, and C. Hui, "Herd instinct of opinion based on dynamic evolutionary game theory," Systems Engineering-Theory \& Practice, vol. 26, no. 2, pp. 275-283, 2011.

[16] M. Rufei and W. Jia, "Dynamic R\&D competition and cooperation: a differential game approach," Science Research Management, vol. 32, no. 5, pp. 36-42, 2011.

[17] K. Wang and S. Wang, "Dynamic game of asymmetry information bargaining with tri-stages bargaining as example," Systems Engineering-Theory \& Practice, vol. 30, no. 9, pp. 1637-1643, 2010 . 


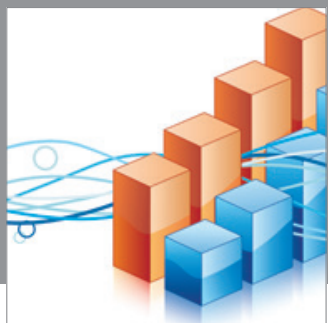

Advances in

Operations Research

mansans

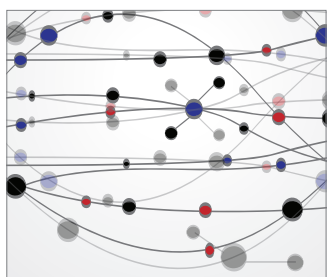

The Scientific World Journal
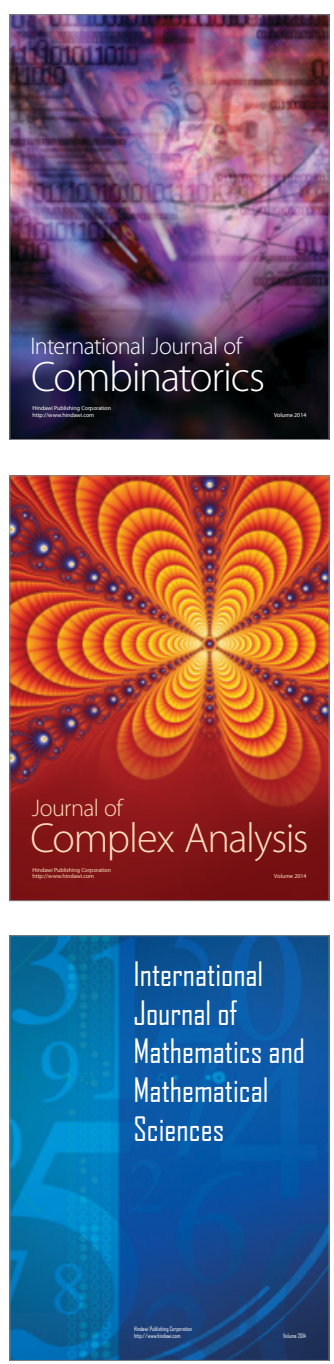
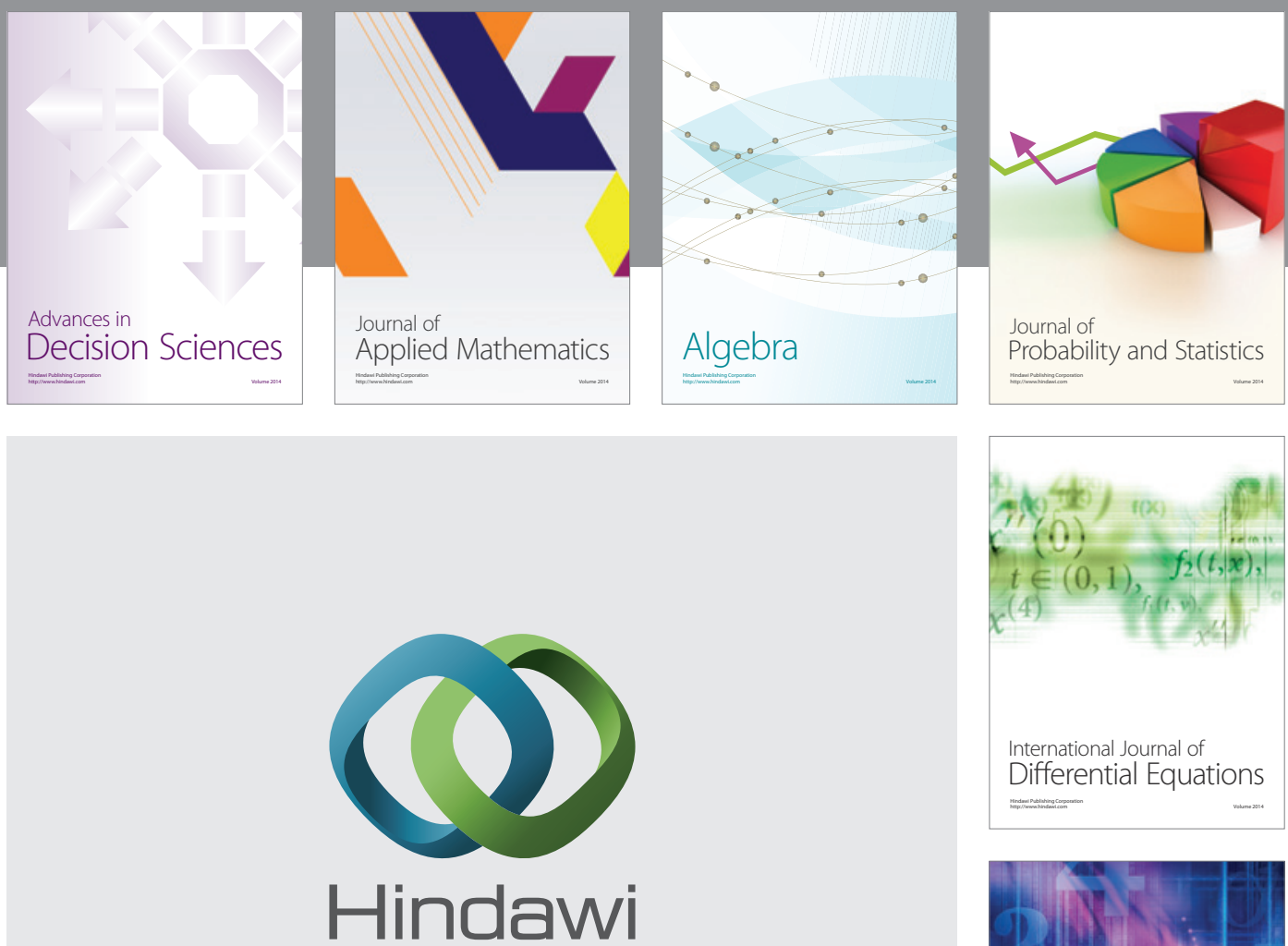

Submit your manuscripts at http://www.hindawi.com
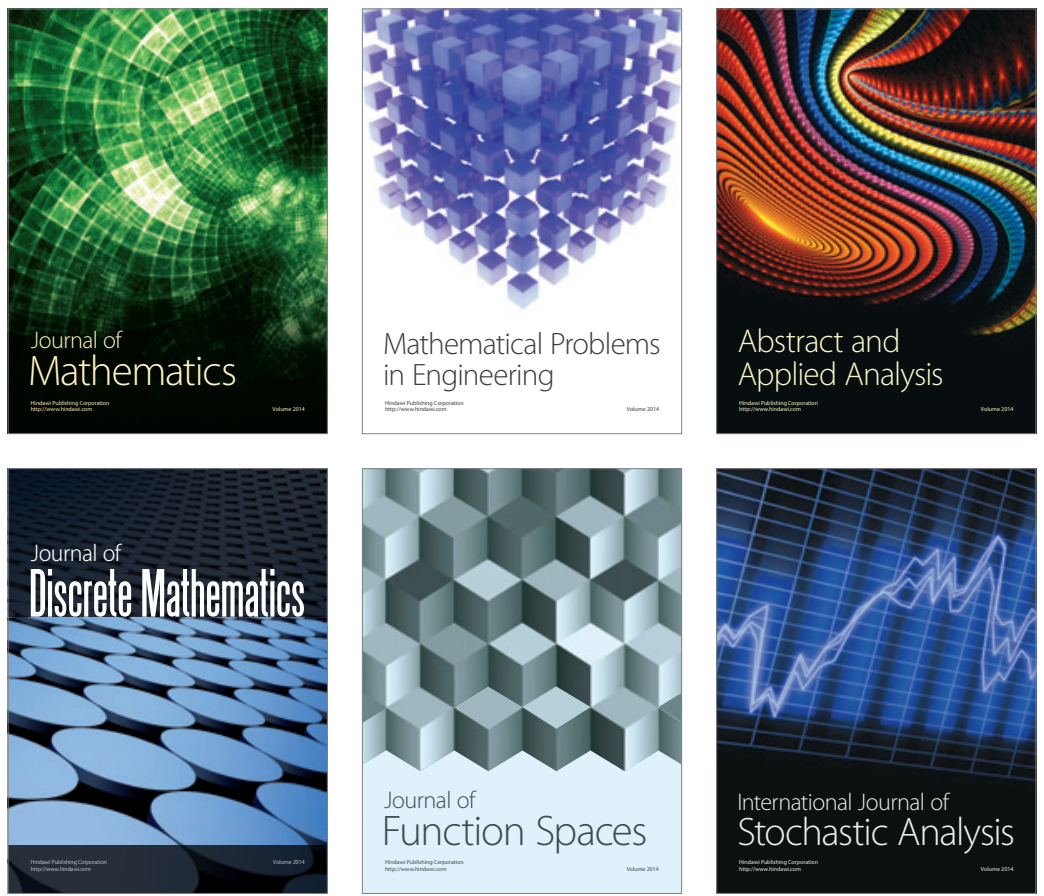

Journal of

Function Spaces

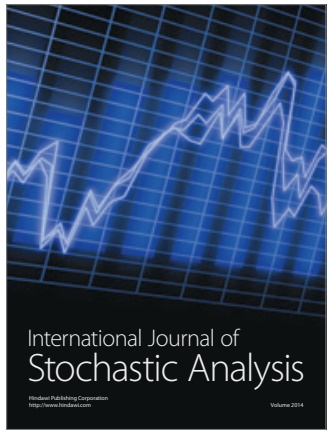

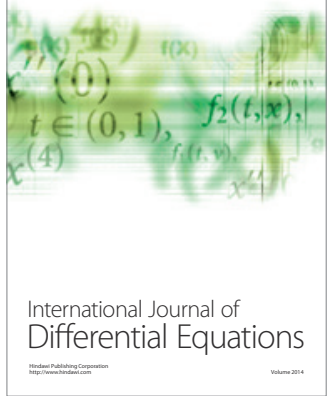
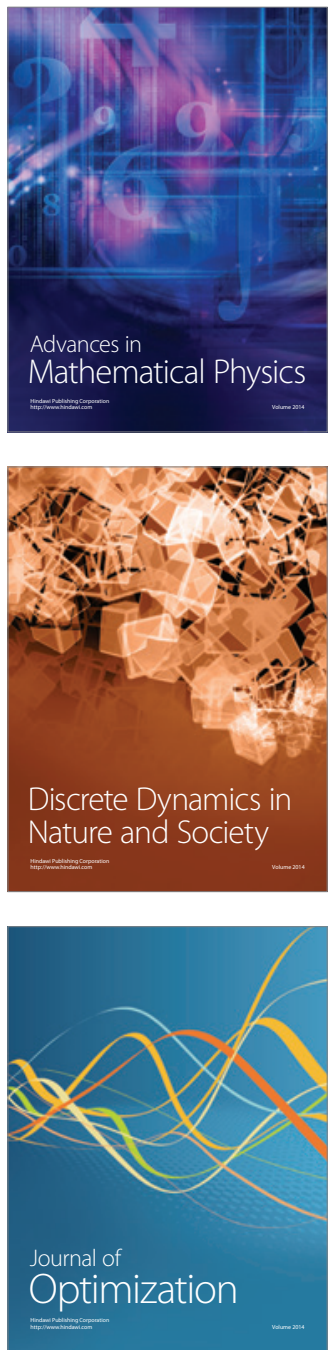